J. Lake Sci.(湖泊科学), 2020, 32(3): 826-839

DOI 10. 18307/2020. 0322

(c) 2020 by Journal of Lake Sciences

\title{
半湿润半干旱流域空间组合模型研究”
}

\author{
刘玉环 ${ }^{1}$, 李致家 ${ }^{1,2 * *}$, 刘志雨 ${ }^{1,3}$, 黄鹏年 $^{4}$ \\ (1:河海大学水文水资源学院, 南京 210098) \\ (2:河海大学水安全与水科学协同创新中心, 南京 210098) \\ ( 3 : 水利部水文局, 北京 100053) \\ (4: 南京信息工程大学水文水资源学院,南京 210044)
}

摘 要: 在半湿润半干旱地区, 下垫面条件复杂,产流机制混合多变, 而现有的水文模型由于其固定的结构和模式,无法 灵活地模拟不同下垫面特征的洪水过程. 本文利用 $C N$-地形指数法将流域划分为超渗主导子流域和蓄满主导子流域. 将 新安江模型 (XAJ)、新安江-Green-Ampt 模型 (XAJG) 和 Green-Ampt 模型 (GA) 相结合,在子流域分类的基础上构建空间组 合模型 $(\mathrm{SCMs})$, 并在半湿润的东湾流域和半干旱的志丹流域进行检验. 结果表明: 东湾流域的参数由水文模型来主导; 而志丹流域的参数受主导径流影响很大. 在东湾流域, 偏蓄满的模型模拟结果优于偏超渗的模型, 且 SCM2 模型 (XAJ 和 XAJG 的组合模型) 的模拟效果最好 (径流深合格率为 $75 \%$, 洪峰合格率 75\%); 而 SCM5 模型 (GA 和 XAJG 的组合模型) 在以超渗产流为主的志丹流域模拟最好 (径流深合格率 53.3\%, 洪峰合格率 53.3\%). 在半干旱半湿润流域, SCMs 模型结 构灵活, 在地形和土壤数据的驱动下, 具有更合理的模型结构和参数, 模拟精度较高, 适应性较强.

关键词: 半湿润半干旱流域;降雨一径流模型;子流域分类;空间组合模型

\section{Spatial combination model for semi-humid and semi-arid watersheds *}

LIU Yuhuan ${ }^{1}$, LI Zhijia ${ }^{1,2 * *}$, LIU Zhiyu ${ }^{1,3} \&$ HUANG Pengnian ${ }^{4}$

(1: College of Hydrology and Water Resources, Hohai University, Nanjing 210098, P.R. China)

(2: National Cooperative Innovation Center for Water Safety \&Hydro-Science of Hohai University, Nanjing 210098, P.R. China)

(3: Bureau of Hydrology, Ministry of Water Resources of China, Beijing 100053, P.R.China)

(4: School of Hydrology and Water Resources, Nanjing University of Information Science \& Technology, Nanjing 210044, P.R. China)

Abstract: Due to the spatial topographic heterogeneity in semi-humid and semi-arid regions, hydrological simulation is always a difficult problem as saturation-excess runoff and infiltration-excess runoff is coexisting during a storm. Most existing hydrological models cannot be customized to simulate flood processes of different areas because of their fixed structures and modes. This study developed a spatial combination model ( SCMs) by combining the Xin'anjiang model ( XAJ), Xin'anjiang-Green-Ampt model (XAJG) and Green-Ampt model (GA) for simulating runoff in the sub-watersheds where either saturation-excess or infiltration-excess runoff mechanism dominates. Curve number-topographic index method was used for dividing a watershed into infiltration-excess dominated and saturation-excess dominated sub-watersheds. The proposed models were tested for two selected watersheds: Dongwan watershed in semi-humid area and Zhidan watershed in semi-arid area. The results showed that the parameters of the Dongwan watershed are dominated by hydrological models, while the parameters of the Zhidan watershed are greatly influenced by the dominant runoff mechanism. The simulation results of the partial saturation-excess models are better than those of partial infiltration-excess models in Dongwan watershed. SCM2 model (combination model of XAJ and XAJG) simulated has the best performance (runoff

* 2019-06-02 收稿;2019-10-25 收修改稿.

国家重点研发计划项目 (2018YFC1508101)、中央高校基本科研业务费专项 (2016B04714) 和国家自然科学基金项 目 (51679061) 联合资助.

** 通信作者;E-mail: zjli@ hhu.edu.cn. 
depth error $R e=75 \%$ and flood peak error $Q e=75 \%$ ), just as the SCM5 model (combination model of GA and XAJG) in Zhidan watershed $(R e=53.3 \%$ and $Q e=53.3 \%)$. In semi-arid and semi-humid watersheds, driven by topography and soil data, the SCMs have a more realistic model structure and parameterization with higher simulation accuracy and stability.

Keywords: Semi-humid and semi-arid watersheds; rainfall-runoff model; sub-watershed classification; spatial combination model

洪水是中国最常见的自然灾害之一, 特别是在中国北方半湿润和半干旱地区, 陡涨陡落的洪水极易造 成严重的生命和财产损失 ${ }^{[1-3]}$. 目前, 多数水文模型在半湿润和半干旱地区的洪水预报表现不佳, 难以为山 洪灾害的防治提供有力的技术支撑 ${ }^{[2]}$. 因此,半湿润和半干旱地区的洪水预报一直是热门的研究课题.

在半湿润和半干旱地区, 由于下垫面和降水时空分布不均匀,超渗产流和蓄满产流随时空变化的现象 尤为明显 ${ }^{[4]}$, 伴随产生的径流被称为混合产流 ${ }^{[5]}$, 使得半湿润和半干旱地区的水文预报比湿润地区更具挑 战性 ${ }^{[6]}$. 近年来国外学者相继开发了 CASC2D 模型 ${ }^{[7]} 、 S C S$ 模型 ${ }^{[8]} 、$ TANK 模型 ${ }^{[9]}$, 并应用于半干旱半湿润地 区, 取得了一定成果, 但单一产流机制的水文模型对于洪水的形成过程反映能力有限. 李致家等 ${ }^{\left[{ }^{[0]}\right.}$ 认为混 合产流模拟的主要困难是识别随时空变化的产流机制. 目前已经开发的混合产流模型,包括垂直混合径流 模型 ${ }^{[5]}$ 、增加超渗的新安江模型 ${ }^{[11]}$ 、新安江一海河模型以及河北雨洪模型 ${ }^{[12]}$ 等. 混合产流模型虽然弥补了 单一产流模型的缺点,但是模型仍然认为每个子流域是固定的产流机制, 难以反映复杂的下垫面情况.

近年来相关学者提出了很多新的建模理论与方法, 其中影响较大的是空间灵活组合建模方法 ${ }^{[13]}$. 该方 法认为流域之间水文、地理、气候等特征差异甚大, 采用统一的或者一成不变的模型架构,模拟不同子流域、 不同类型的产汇流过程, 是不恰当的 ${ }^{[14]}$, 应根据流域的主导水文过程, 灵活及时地调整模型结构, 以确保每 个流域可以使用适当的模型结构 ${ }^{[15]}$. 目前,多模式的灵活框架已被用于探讨及解决水文模拟中的各种难 题 ${ }^{[16-17]}$. 基于主导的水文过程, Savenije ${ }^{[14]}$ 提出了一个概念性模型 (FLEX-Topo) 用于阐明水文过程的复杂性. Clark 等 ${ }^{[18]}$ 利用 FUSE 框架, 构建了 79 个概念性模型, 用于挪威 Narsjø 流域,研究了低水形成机理. Buytaert 和 Beven ${ }^{[19]}$ 结合高山草原地区的水文特征, 通过灵活地增加或减少模型的组成部分来研究洪峰的季节性变 化. Gao 等 ${ }^{[20]}$ 通过 4 个降雨一径流模型, 验证了地形可以反映主导水文过程的假设. 上述这些领域的应用为 半湿润地区模拟研究提供了新思路,李致家等 ${ }^{[10]}$ 用新安江模型和河北模型研究了半湿润地区模型的空间组 合问题. 他们提出的 $C N$-地形指数法通过结合流域地形、土地利用和土壤特性可以简单而有效地对子流域进 行蓄满和超渗的划分,但是子流域分类后,由于模型种类少,选择固定,难以适应复杂的下垫面的洪水模拟. 此外,相比河北模型,Green-Ampt 模型没有壤中流和地下径流,更适合于北方干旱、半干旱流域.

本文旨在探索适用于半湿润和半干旱地区的空间组合模型框架, 通过 $C N$-地形指数法 ${ }^{[10]}$ 对研究区的子 流域进行分类,采用 3 种代表性模型: 新安江模型、新安江-Green-Ampt 模型和 Green-Ampt 模型来构建空间 组合模型 (SCMs), 并在我国半湿润的东湾流域和半干旱的志丹流域进行验证和分析.

\section{1 模型与方法}

\section{1 子流域分类}

气象因子和下垫面因子决定了径流产生的机制 ${ }^{[14]}$. 如果将流域划分为足够小的子流域, 则蓄满径流或 超渗径流将成为子流域的主导径流机制. 本文采用 $C N$-地形指数法, 将研究流域划分为蓄满主导或超渗主导 子流域. $C N$ 指标 ${ }^{[21]}$ 源自 SCS 模型, 表示某种土壤水分条件下的曲线数, 用来描述直接径流产生的难易程 度, $C N$ 值越大, 发生超渗径流的可能性越大. 地形指数 ${ }^{[22]}$ 反映流域上每点长期的土壤水分状况, 可以描述 蓄满产流发生的难易程度,地形指数大的区域容易发生蓄满产流. 根据 DEM、土壤和土地利用数据,计算每 个子流域的 $C N$ 值和地形指数, 先根据 $C N$ 值进行初始分类 (当 $C N$ 值小于 60 时, 将子流域划分为蓄满主导 子流域, 否则划分为超渗主导子流域), 再使用地形指数值进一步修改 (当蓄满主导子流域的地形指数 $<7$ 时, 将该子流域修改为超渗主导子流域; 当地形指数 $>25$ 时, 将超渗主导子流域修改为蓄满主导子流域), 最 终得到每个子流域的主导径流类型.

\section{2 水文模型}

本文选择了 3 种代表性模型: 新安江模型、Green-Ampt 模型和新安江-Green-Ampt 模型. 这些模型的参 
数数量少且具有明确的物理意义. 模型计算所需数据少, 计算精度高, 已广泛应用于很多地区 ${ }^{[23]}$. 另外, 3 个 模型的结构相似,模型的部分参数相同, 可以保证模型之间的耦合.

1.2.1 新安江模型 新安江模型 ${ }^{[24]}$ (简称 XAJ 模型) 是一个经典的概念性水文模型, 核心是基于抛物线概率 分布的降雨一径流本构关系, 先产流, 后分水源. 模型由蒸散发、产流、分水源和汇流 4 个模块, 17 个参数组 成. 新安江模型原理简单明确,计算效率高, 被广泛应用于中国湿润地区的洪水预报 ${ }^{[25]}$.

1.2.2 Green-Ampt 模型 在半湿润半干旱以及干旱地区特别容易发生历时较短, 强度大的暴雨, 并产生陡涨 陡落的洪水过程, 因此, 需要考虑使用超渗产流模型进行模拟. Green 和 $A m p{ }^{[26]}$ 于 1911 年提出了积水条件 下均质土壤下渗模型—Green-Ampt 模型 (简称 GA 模型). 模型具有表达式简单、参数较少和物理意义明 确等特点,计算结果精度较高,应用广泛.

1.2.3 新安江-Green-Ampt 模型 实际上, 半干旱和半湿润地区以及久旱之后的湿润地区都会发生超渗现象. 在新安江模型中, 只考虑了蓄满区域的径流, 忽略了非蓄满区域的超渗地表径流. 针对这一问题, 新安江Green-Ampt 模型 ${ }^{[7]}$ (XAJG 模型) 被提出. 该模型考虑在蓄满面积上发生的产流采用蓄水容量曲线计算, 未 蓄满面积上的产流采用 Green-Ampt 下渗容量曲线计算.

\section{3 空间组合模型 ( SCMs)}

本文通过组合 3 种降雨一径流模型: 新安江模型 (蓄满产流)、Green-Ampt 模型 (超渗产流) 和新安江Green-Ampt 模型 (混合产流), 提出了一种空间组合模型, 称为 $\operatorname{SCMs}$ (图 1). 通过子流域分类, 研究区被划分 为超渗主导区域和蓄满主导区域, 将 SCMs 模型应用于研究区, 对洪水过程进行模拟. 统计模拟结果, 通过与 实测流量对比,最终选出模拟效果最优的 SCM 模型.

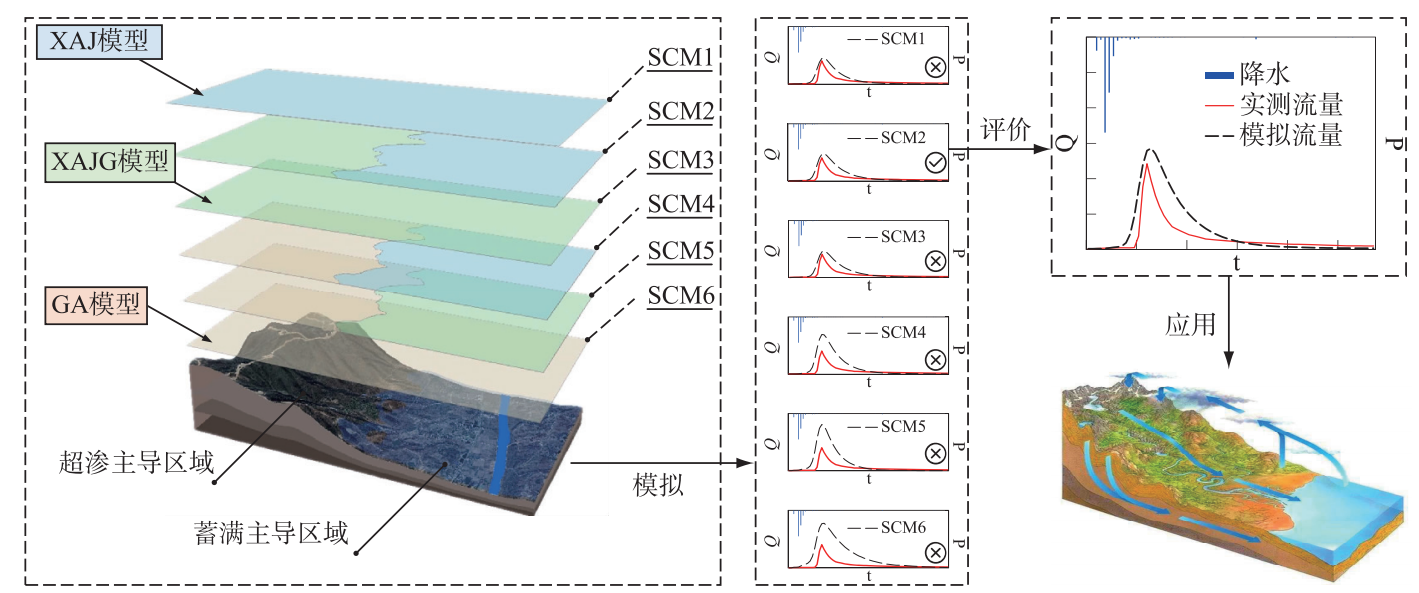

图 1 空间组合模型原理

Fig. 1 Theory of spatial combination models

子流域分类后, 对每个子流域标记选择的产流计算模型 (表 2), 3 种模型的标记码分别为 $1 、 2 、 3$. 被标记 的子流域通过标记码, 选择对应的产流模型进行计算. 例如, SCM2 模型是由 XAJ 模型和 XAJG 模型组合而 来, 蓄满主导子流域选择 XAJ 模型, 而超渗主导子流域则选择 XAJG 模型. 最终, 可以得到 6 种 SCM 模型. 其

表 1 空间组合模型组合情况

Tab.1 Combination of spatial combination models

\begin{tabular}{cccccccc}
\hline 模型 & 标记 & SCM1 & SCM2 & SCM3 & SCM4 & SCM5 & SCM6 \\
\hline XAJ 模型 & 1 & $V$ & $V$ & & $\checkmark$ & & \\
GA 模型 & 2 & & & & $V$ & $V$ & $\checkmark$ \\
XAJG 模型 & 3 & & $V$ & $V$ & & $V$ & \\
\hline
\end{tabular}


中,SCM1、SCM3 或 SCM6 只选择一种模型,称为非组合模型. 而 SCM2、SCM4 或 SCM5 选择了两种模型,称为组 合模型. 6 种 SCMs 模型的产流模式由蓄满产流逐渐过渡为超渗产流, 即蓄满产流在产流计算中所占比例逐渐 下降, 在 SCMs 中蓄满比例大的为偏蓄满模型 (SCM1 和 SCM2), 蓄满比例小的为偏超渗模型 (SCM5 和 SCM6). 1.3.1 模型构建 SCMs 模型主要分为蒸散发、产流、水源划分以及汇流 4 个计算模块. 1) 蒸散发模块: 除 GA 模型外,蒸散发采用三层蒸发模型,计算蒸发量并更新土壤含水量. 2) 产流模块: 当子流域选择 XAJ 模型, 产 生径流是蓄满径流 (由蓄水容量分布曲线计算) ; 当子流域选择 GA 模型时, 产生径流是超渗地面径流 (由 Green-Ampt 下渗公式计算) ; 当子流域选择 XAJG 模型时, 产生径流是混合径流 (由蓄水容量分布曲线和 Green-Ampt 下渗公式计算). 3) 水源划分模块:XAJ 和 XAJG 模型采用自由水容量曲线划分地表径流、地下 径流以及壤中流; GA 模型只产生超渗地面径流. 4) 汇流模块: 在每个子流域内, 地表径流 (饱和地面径流和 超渗地面径流) 直接进人河网. 壤中流和地下径流通过滞后演算法计算到达子流域的出口. 最后, 通过马斯 京根法进行河道演算, 得到流域出口断面的洪水过程. SCMs 模型根据上述内容, 采用 VB 语言进行编写, 并 采用高耦合、低内聚模式, 将蒸散发、产流、水源划分以及汇流计算模块化, 在运行过程中灵活调用. SCMs 模 型的实现结构如图 2 所示.

1.3.2 模型参数 SCMs 包含 22 个参数, 与 XAJ 和 GA 模型一致 ${ }^{[26-27]}$ (表 2). 它们具有明确的物理意义并且 彼此独立, 取值决定于模型的组合方式. 为了减少率定过程中参数的不确定性, 减轻计算工作量, 本文仅对 敏感参数 (表 2 加粗显示) 使用 SCE-UA 算法 ${ }^{[28]}$ 自动优化, 不敏感参数由人工试错法估计.

1.3.3 模型校准和评估 依据传统的水文模拟与预报精度评定准则, 结合半湿润半干旱地区洪水特征, 参考 《水文情报预报规范》 ${ }^{[29]}$ 规定, 选择 4 种评价指标: 径流深相对误差 $(R e)$, 该误差以实测值的 $20 \%$ 作为许可 误差, 当该值大于 $20 \mathrm{~mm}$ 时取 $20 \mathrm{~mm}$, 当小于 $3 \mathrm{~mm}$ 时取 $3 \mathrm{~mm}$; 洪峰相对误差 ( $Q e$ ), 以实测洪峰的 $20 \%$ 作为 许可误差判定预报洪峰是否合格; 峰现时间误差 $(T e)$, 以峰现时间小于 $3 \mathrm{~h}$ 为许可误差; 确定性系数 $(D c)$, 评价洪水实测过程与预报过程之间的拟合程度. 在半湿润半干旱地区, 洪水陡涨陡落, 洪量小但洪峰高, 需 要更加关注洪峰模拟效果. 因此, 本次模拟评价将径流深合格数、洪峰合格数与峰现时间误差作为主要的评 价指标, 确定性系数作为参考指标 (图 2).

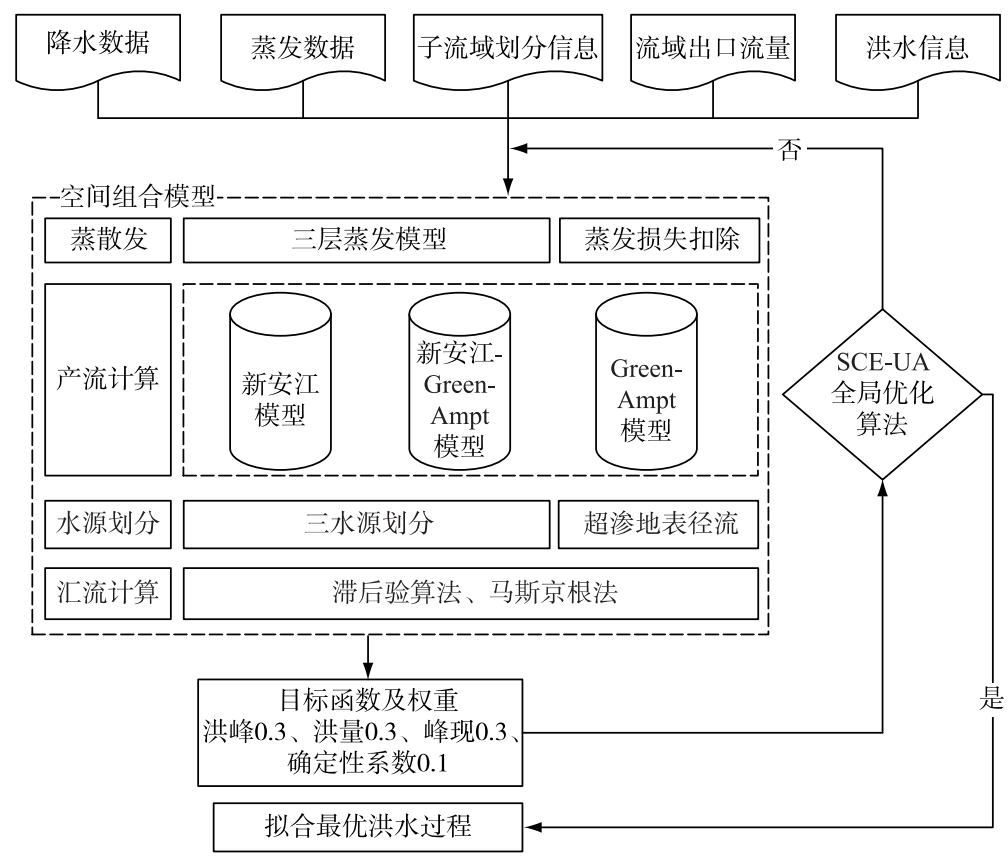

图 2 空间组合模型结构

Fig.2 Components of the spatial combination models 


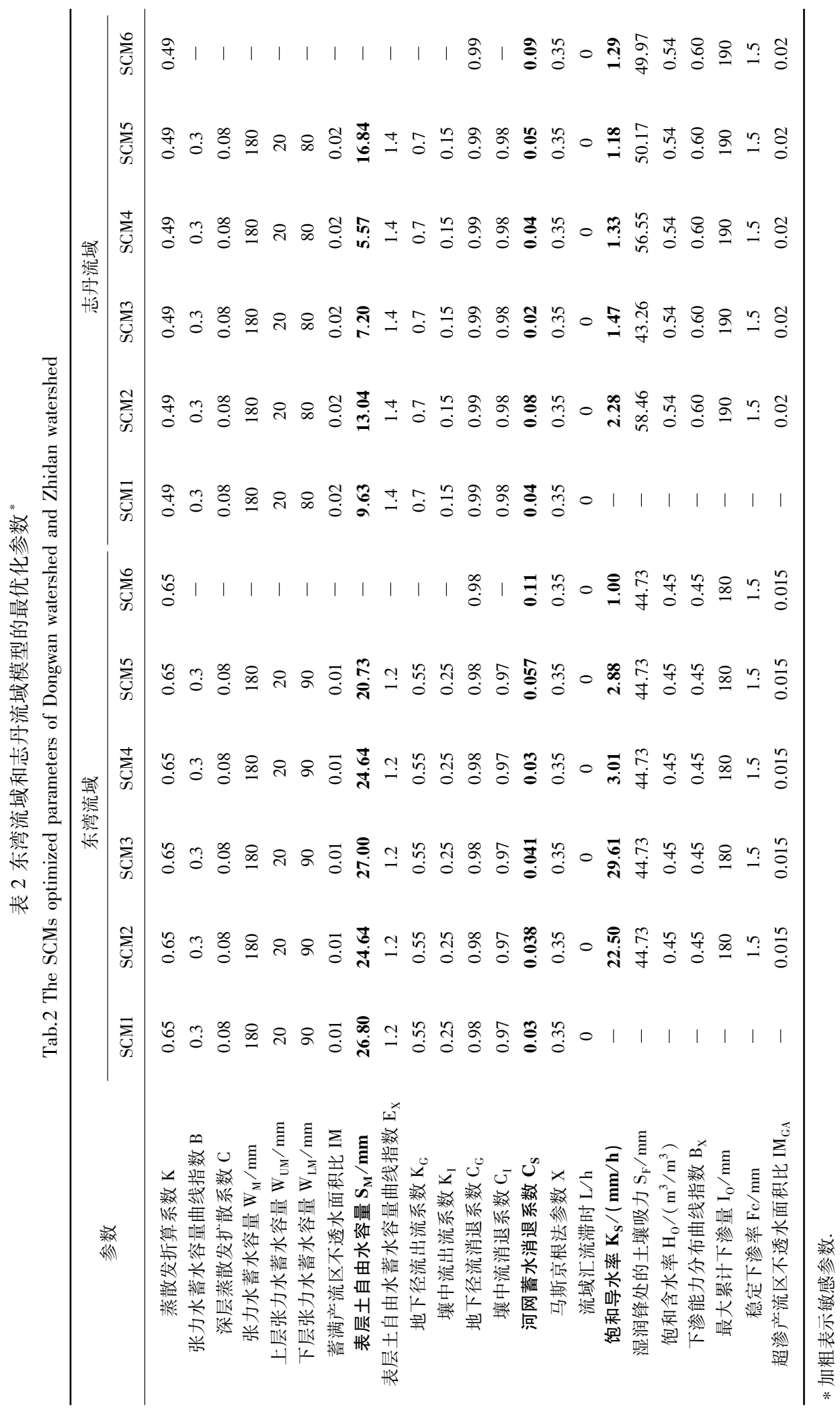




\section{2 研究流域和数据处理}

\section{1 研究流域}

东湾流域 (图 3a) 位于伊河河源地区, 流域面积 $2856 \mathrm{~km}^{2}$. 属于大陆性季风气候, 是半湿润地区. 降雨量 分布不均匀, 流域内多年平均降水量为 $773 \mathrm{~mm}$, 日降水量一般在 $100 \mathrm{~mm}$ 以上, 最大值可达 $600 \mathrm{~mm}$. 暴雨主 要集中在 7-8 月, 占总降水量的 $60 \%$. 多年平均蒸发量为 $564 \mathrm{~mm}$. 流域地势西高东低, 上游植被良好, 主要 为林地, 下游河道附近裸地较多.

志丹流域 (图 3b) 位于黄河流域北洛河水系, 流域面积 $774 \mathrm{~km}^{2}$. 属于大陆性季风气候, 是半干旱地区. 流域内多年平均降水量为 $510 \mathrm{~mm}$, 夏季降水多为量大时急的暴雨, 多年平均径流量为 $3.23 \times 10^{7} \mathrm{~m}^{3}$. 流域地 形支离破碎,地势北高南低,坡度变化大. 河床由黄土夹沙卵石组成, 河流穿行于黄土沟警之间, 由于黄土疏 松易冲刷,形成树枝状水系.

\section{2 数据}

本文所需下垫面数据为数字高程地图 (DEM)、土壤类型和土地利用类型数据. DEM 从地理空间数据云 网站下载, 选择 GDEMV2 DEM 数字高程数据产品, 分辨率为 $30 \mathrm{~m}$. 土壤数据来源于联合国粮农组织 (FAO) 1:100 万土壤栅格数据资料. 土地利用数据可从美国地质勘探局 (United States Geological Survey, 简称 USGS) 网站下载,数据为分辨率为 $1 \mathrm{~km}$ 的矢量文件.

研究流域水文数据包括降雨、蒸发及流量数据 (时段为 $1 \mathrm{~h}$ ), 由黄河水利委员会水文局以及陕西省水文 局提供. 东湾流域选择 1994-2011 年 16 场次洪水资料进行模拟, 12 场洪水率定,4 场验证. 流量数据来自 东湾水文站, 降雨资料来自潭头等 8 个雨量站 (图 3a). 志丹流域选取 2000-2014 年 20 场次洪水进行模拟, 15 场洪水率定, 5 场验证. 流量数据来自志丹水文站,降雨资料来自野鸡岔等 7 个雨量站 (图 $3 \mathrm{~b}$ ).
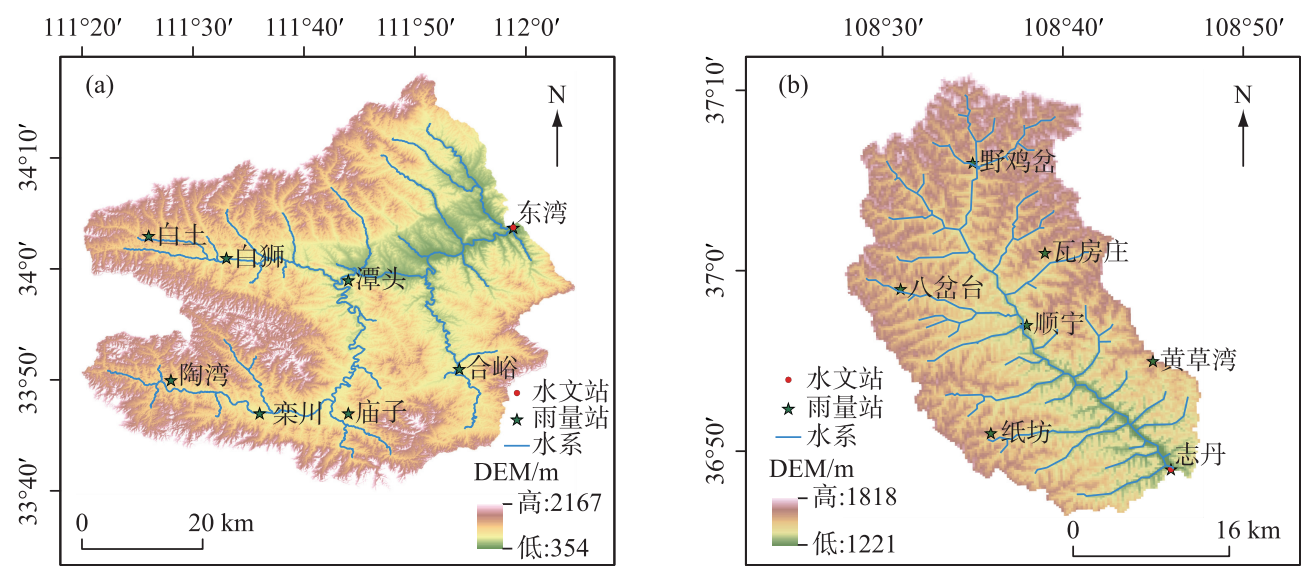

图 3 东湾流域 (a) 和志丹流域 (b) 的地形、水系以及水文站点分布

Fig.3 Topography, river and station of Dongwan watershed (a) and Zhidan watershed (b)

\section{3 数据预处理}

为方便计算 $C N$ 值, 根据土壤特性和水文特征将土壤数据重分类为 4 组 $(\mathrm{A} 、 \mathrm{~B} 、 \mathrm{C} \text { 和 } \mathrm{D})^{[10]}$. 东湾流域 $78 \%$ 的土壤属于 $\mathrm{B}$ 类( 中等人渗率), 主要集中在上游地区. A 类土壤( 高渗透率) 占 $21 \%$, 主要分布在下游地 区 (图 4a). 志丹流域的土壤类型分为 B、C 两类 (图 4b) : 其中 B 类土占 $96 \%, C$ 类分布在流域出口附近, 占 $4 \%$ (低人渗率).

东湾流域土地利用有 5 种类型: 林地 ( $82.2 \%$ )、未利用地 (10.4\%) 以及耕地、水体和建筑用地 $(7.4 \%)$ (图 5a). 上游地区主要由森林覆盖, 河道下游地区附近有许多裸地. 志丹流域有 5 种土地利用类型: 耕地 (51\%)、草地 (39\%) 以及灌木、草原和山坡草地 (10\%)（图 5b). 

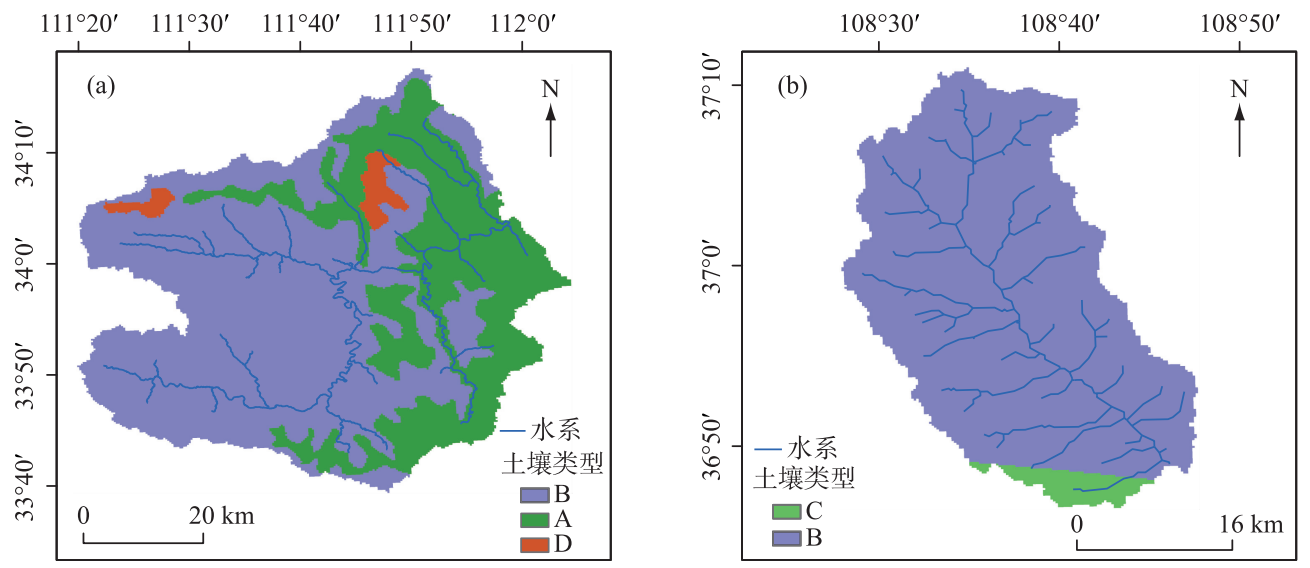

图 4 东湾流域 ( a ) 和志丹流域 (b) 的土壤类型分布

Fig.4 Distribution of soil types in Dongwan watershed (a) and Zhidan watershed (b)
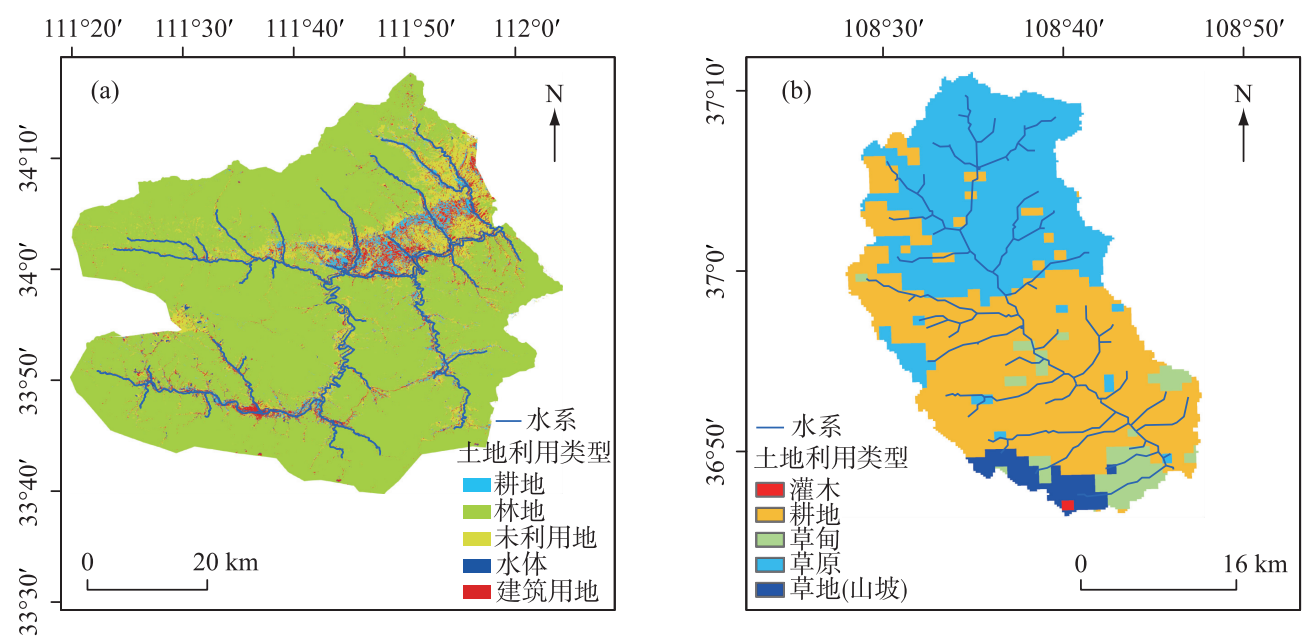

图 5 东湾流域( a) 和志丹流域( b) 的土地利用类型分布

Fig.5 Distribution of land use types in Dongwan watershed (a) and Zhidan watershed (b)

\section{3 结果与讨论}

\section{1 子流域分类}

根据 DEM 数据划分子流域, 东湾流域划分为 52 个子流域, 面积最大的为 $134 \mathrm{~km}^{2}$, 最小的为 $10 \mathrm{~km}^{2}$; 志 丹流域划分为 31 个子流域, 面积最大的为 $47 \mathrm{~km}^{2}$, 最小的为 $11 \mathrm{~km}^{2}$. 采用 $C N$-地形指数法 ${ }^{[10]}$ 将子流域进行 分类.

对于东湾流域,超渗主导子流域主要分布在上游和下游河道的西侧, 占流域面积的 50\%左右(图 6a). B 类土壤在上游区域占主导地位, $C N$ 值较大, 因此被划分为超渗主导子流域. 下游河道西侧的子流域划分情 况较为复杂, 虽然 $\mathrm{A}$ 类土壤在该区所占比例较大, $C N$ 值本应偏小, 但实际情况却相反, 这种现象是未利用地 和建筑用地的植被稀缺造成的,因此下游河道西侧的子流域被划分为超渗产流主导.

对于志丹流域, 超渗主导子流域占流域总面积的 $68 \%$ 左右, 主要集中在上游、中游东部以及下游西部区 域 (图 6b). 流域上游坡度大, 导致下渗量小; 下游西部区域以 $\mathrm{C}$ 类土为主, 人渗能力较低, 灌木林保水能力 
差, $C N$ 值偏大,被划分为超渗产流主导区域. 中游流域 $\mathrm{B}$ 类土占比较大, $C N$ 值较大, 因此子流域往往会出现 蓄满产流. 但是, 中游东部的子流域地形指数偏小, 因此修改为超渗子流域.
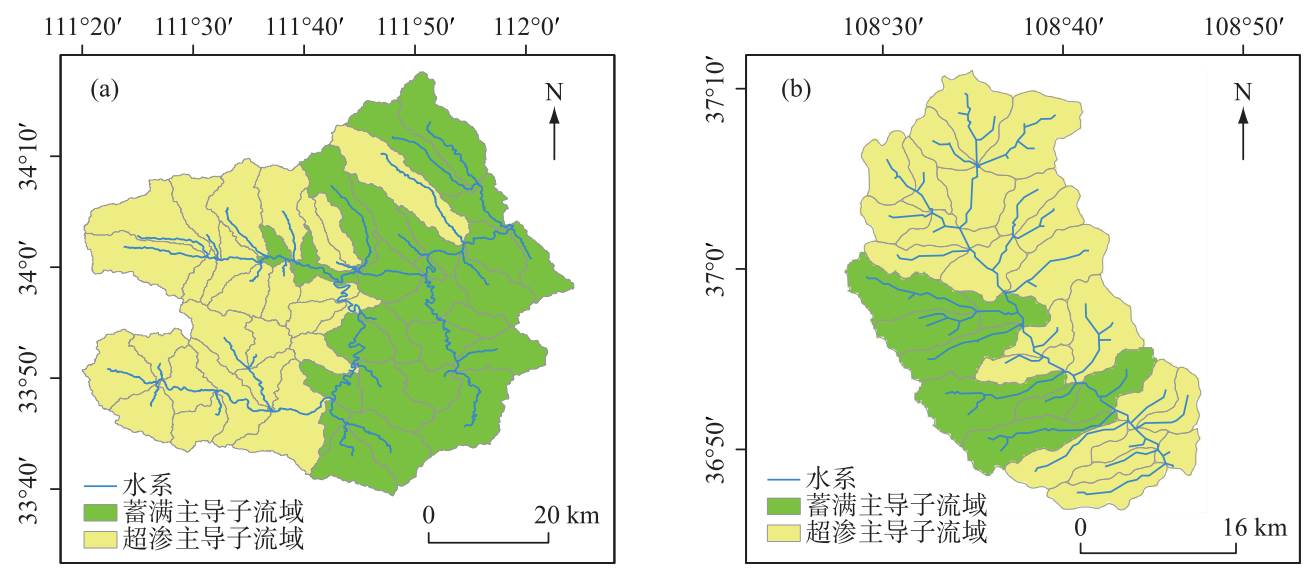

图 6 东湾流域 $(\mathrm{a})$ 和志丹流域 $(\mathrm{b})$ 子流域分类结果

Fig.6 Sub-watershed classification results of Dongwan watershed (a) and Zhidan watershed (b)

\section{2 模型参数分析}

3.2.1 敏感参数 从 6 种 SCMs 模型在东湾流域和志丹流域的参数率定结果可以发现, SCMs 模型参数分为 蓄满产流以及超渗产流两部分, 汇流的参数基本一致(表 2). 具体分析后, 得到以下结论:

1) 自由水容量 $S_{M}$. 自由水容量 $S_{M}$ 在新安江模型中对于次洪模拟影响较大, $S_{M}$ 值越大, 产生的洪量越小. 从表 2 可以看出, 东湾流域的 $\mathrm{S}_{\mathrm{M}}$ 值是志丹流域的 $2 \sim 3$ 倍, 且变化趋势比较稳定, 取值介于 $20.73 \sim 27.00$ 之 间. 志丹流域的 $\mathrm{S}_{\mathrm{M}}$ 值变化波动较大, 最小值为 7.20 , 最大值为 16.84 . 说明 $\mathrm{S}_{\mathrm{M}}$ 值在东湾流域比在志丹流域控 制径流的效果更加明显,起主导作用.

对于东湾流域, 6 种 SCMs 模型中蓄满产流部分所占比例越大, 则 $\mathrm{S}_{\mathrm{M}}$ 值越大, 但 SCM3 模型与 SCM4 模型 例外, 这是因为 SCM3 模型在计算产流时, 全部子流域采用的是 XAJG 模型. SCM3 模型计算的径流量包含蓄 满产流的水量和 GA 下渗公式计算的水量, 在三水源划分时, 自由水容量值 $\mathrm{S}_{\mathrm{M}}$ 会偏大一些. SCM4 模型在蓄 满主导子流域采用 XAJ 蓄满产流计算, 在超渗主导子流域采用 GA 超渗产流计算, 其中超渗产流部分以稳 定下渗率划分水源, 因此 $\mathrm{S}_{\mathrm{M}}$ 值偏小一些.

志丹流域的 $\mathrm{S}_{\mathrm{M}}$ 值取值普遍偏小但波动较大. 说明在蓄满产流计算完毕进行水源划分时, 为保证得到足 够的地表径流, 提高模拟洪水的洪峰, 参数 $\mathrm{S}_{\mathrm{M}}$ 需取较小值. 从 6 种 $\mathrm{SCMs}$ 模型的 $\mathrm{S}_{\mathrm{M}}$ 值分布来看, $\mathrm{S}_{\mathrm{M}}$ 值没有呈 现一定的变化规律, 说明 $\mathrm{S}_{\mathrm{M}}$ 值在志丹流域径流划分中未起主导作用.

2 ) 地表径流消退系数 $\mathrm{C}_{\mathrm{S}}$. 参数 $\mathrm{C}_{\mathrm{S}}$ 反映洪水坦化程度 ${ }^{[24]}, \mathrm{C}_{\mathrm{S}}$ 值越小, 模拟的洪峰越大, 洪水过程越尖瘦. 两个流域的 $\mathrm{C}_{\mathrm{S}}$ 值都小于 0.11 ,变化幅度不大,符合半湿润半干旱地区洪水陡涨陡落的特点.

在东湾流域, 6 种 $\mathrm{SCMs}$ 模型的 $\mathrm{C}_{\mathrm{s}}$ 值随着蓄满产流比例的减小而逐渐增大. 蓄满产流需要先补充土壤缺 水量, 只有在土壤含水量达到田间持水量后才产流. 偏蓄满模型计算时, 需要减小 $\mathrm{C}_{\mathrm{S}}$ 值以提高洪水模拟的洪 峰值, 达到较好的模拟效果. 超渗产流下渗补充土壤含水量非常少, 基本上都发生了产流, 相比之下 $\mathrm{C}_{\mathrm{S}}$ 值较 大一些.

在志丹流域, $\mathrm{C}_{\mathrm{S}}$ 取值在 $0.02 \sim 0.08$ 之间, 相比东湾流域较小, 但是各模型之间相差不大, 说明参数 $\mathrm{C}_{\mathrm{S}}$ 在 流域汇流计算时影响程度有所降低. 另外, XAJ 模型和 XAJG 模型中滞后演算法描述的是河网对洪水的调蓄 作用, 而 $\mathrm{GA}$ 模型没有此项功能, 为了弥补这一缺陷, 其滞后演算法描述的其实是整个流域对洪水的调蓄作 用,因而 SCM6 模型河网水流消退系数 $\mathrm{C}_{\mathrm{S}}$ 值较大.

3 ) 土壤饱和导水率 $K_{\mathrm{S}}$. 参数 $\mathrm{K}_{\mathrm{S}}$ 表示在土壤饱和状态下,单位时间可传导的水量, 是 $\mathrm{GA}$ 模型中的参数. 参数 $\mathrm{K}_{\mathrm{S}}$ 对洪峰影响比较明显, 取值越小, 峰值越大. 从表 2 可以发现, 在东湾流域, 随着超渗产流比例的增 
加, 饱和导水率 $\mathrm{K}_{\mathrm{s}}$ 逐渐减小. 此外, 当 $\mathrm{SCM}$ 模型中加人 $\mathrm{GA}$ 模型后, $\mathrm{K}_{\mathrm{s}}$ 值急剧下降 (从 $20 \mathrm{~mm} / \mathrm{h}$ 下降至 3 $\mathrm{mm} / \mathrm{h}$ ), 可以看出, 参数 $K_{\mathrm{s}}$ 在 $\mathrm{GA}$ 模型中十分敏感.

在志丹流域, 土壤饱和导水率 $\mathrm{K}_{\mathrm{S}}$ 取值在 $1 \sim 3 \mathrm{~mm} / \mathrm{h}$ 之间, 但随着超渗产流比例的增加, $\mathrm{K}_{\mathrm{S}}$ 值呈现出略微 下降的趋势. 与东湾流域相比, 志丹流域的参数 $\mathrm{K}_{\mathrm{S}}$ 取值比较稳定且差距较小, 说明参数 $\mathrm{K}_{\mathrm{s}}$ 在志丹流域影响 较大, 是主导参数.

3.2.2 不敏感参数 由于东湾流域和志丹流域是典型的半湿润半干旱流域, 其洪水过程的地表径流和地下径 流十分明显, 壤中流比例小, 洪水陡涨陡落, 退水速度快, 基本在 1 天左右. 为了减少率定过程中参数的不确 定性, 固定不敏感参数的取值, 保证模型参数具备物理意义, 仔细研究了部分不敏感参数的取值:

1) 壤中流出流系数 $\mathrm{K}_{\mathrm{I}}$ 和地下径流出流系数 $\mathrm{K}_{\mathrm{G}}$ 相互约束, 两者之和与退水天数呈倒数关系 ${ }^{[27]}$. 为使模 拟的洪水呈现陡落过程, 需加快退水速率. 东湾流域选择 $\mathrm{K}_{\mathrm{I}}+\mathrm{K}_{\mathrm{G}}=0.8$. 志丹流域选择 $\mathrm{K}_{1}+\mathrm{K}_{\mathrm{G}}=0.85$, 其中地下 径流比例较大, $\mathrm{K}_{\mathrm{G}}$ 取值偏大一些.

2) 壤中流消退系数 $\mathrm{C}_{1}$ 与地下径流消退系数 $\mathrm{C}_{\mathrm{G}}$ 的取值与消退时间呈倒数关系 ${ }^{[27]}$. 考虑到志丹流域洪水 陡涨陡落,退水过程仅几个小时, 因而在率定壤中流和地下径流的消退系数时, 取值偏大.

综上所述, SCMs 模型在东湾流域的参数取值由其主导水文模型决定. 例如, 对洪峰影响较大的参数 $\mathrm{C}_{\mathrm{S}}$ 、 $\mathrm{K}_{\mathrm{S}}$, 当蓄满产流比例大时, $\mathrm{C}_{\mathrm{S}}$ 对洪峰影响明显, 当超渗产流比例大时, $\mathrm{K}_{\mathrm{s}}$ 对洪峰影响明显.

与半湿润的东湾流域相比, 志丹流域的超渗产流面积比例较大, 率定的参数已具有明显的共性, 尽管模 型结构有所差异, 但在模型参数取值趋势方面较为一致, 说明在流域水文过程主导的产流机制下, 参数不再 受限于模型结构.

\section{3 模型结果分析}

3.3.1 模型率定和验证 在东湾流域, SCM2 模型的前 3 种统计指标在率定期和验证期都是最高的, 模拟结 果最好 (表 3). SCM 2 模型的 $D c$ 在率定期和验证期分别为 0.74 和 0.28 , 与 SCM 1 模型和 SCM3 模型相差不 大. 峰现时间合格率界限比较明显, 偏蓄满的模型平均误差小 (91.6\% 和 50\%), 偏超渗的模型误差比较大 ( $83.3 \%$ 和 $25 \%$ ). SCM6 模型的 4 个评价指标在率定期和验证期都是最低的, 特别是在预测洪峰时, 模拟效 果较差. 根据图 5a 可知, 东湾流域的林地占比达到 $82.2 \%$, 在林地丰富的区域, 土壤包气带较薄, 容易发生蓄 满产流 $^{[12]}$, 因而全部为超渗产流的 SCM6 模型难以准确地模拟, 说明蓄满产流机制对东湾流域是不可缺的. 综上所述,在东湾流域, 偏蓄满模型(SCM1 和 SCM2) 表现优于偏超渗模型(SCM5 和 SCM6).

表 3 东湾流域 6 种 SCMs 模型的评价统计

Tab.3 Evaluation statistics for six SCMs models in Dongwan watershed

\begin{tabular}{|c|c|c|c|c|c|c|c|c|}
\hline \multirow{2}{*}{ 模型 } & \multicolumn{4}{|c|}{ 率定期 } & \multicolumn{4}{|c|}{ 验证期 } \\
\hline & $\mathrm{Re} / \%$ & $Q e / \%$ & $\mathrm{Te} / \%$ & $D c$ & $\mathrm{Re} / \%$ & $Q e / \%$ & $\mathrm{Te} / \%$ & $D c$ \\
\hline SCM1 & 66.7 & 66.7 & 91.6 & 0.74 & 50 & 50 & 50 & 0.29 \\
\hline SCM2 & 75.0 & 75.0 & 91.6 & 0.74 & 75 & 75 & 50 & 0.28 \\
\hline SCM3 & 66.7 & 58.3 & 91.6 & 0.76 & 50 & 50 & 50 & 0.31 \\
\hline SCM4 & 58.3 & 58.3 & 83.3 & 0.35 & 25 & 50 & 25 & 0.05 \\
\hline SCM5 & 41.6 & 41.6 & 83.3 & 0.13 & 25 & 25 & 25 & 0.01 \\
\hline SCM6 & 41.6 & 33.3 & 83.3 & -0.01 & 25 & 25 & 25 & -1.93 \\
\hline
\end{tabular}

在志丹流域, 下垫面覆盖多为土层较薄的草地, 土壤保水能力差, 极易发生超渗产流, 加上地表沟壀纵 横, 使得汇流速度加快, 因而多易出现陡涨陡落的洪水过程. 在以往学者的研究中可以看出, 志丹流域的洪 水过程模拟十分困难 ${ }^{[00-32]}$. 在本次模拟中也出现相同的情况: SCMs 模型的模拟结果较差, 洪峰合格率 $Q e$ 和 径流深合格率 $R e$ 很低, 但随着模型中超渗比例的增加, 偏超渗模型 (SCM5 和 SCM6) 的模拟精度有所提高. 在率定期, SCM 5 模型和 SCM6 模型的 $Q e$ 和 $R e$ 均超过 46.6\%, 但在验证期, 5 个洪水事件中只有两个是合格 的 (表 4). 志丹流域的洪水过程是陡涨陡落的, 而模型模拟的洪水常是缓涨缓落,洪水过程形态的差异, 使 模拟结果的径流深虽合格, 但峰值的误差却非常大. 因此, 在模拟洪水时, 不仅要确保径流深在允许误差范 
围内,还要尽可能提高洪峰的合格率. 峰现时间误差 $T e$ 在率定期内没有显著变化,介于 $70 \% \sim 90 \%$ 之间. 确 定性系数 $D c$ 普遍很差, 说明在半干旱地区, 确定性系数不能描述陡涨陡落的洪水过程. 综上所述, 在志丹流 域偏超渗模型的模拟结果优于偏蓄满模型.

表 4 志丹流域 6 种 SCMs 模型的评价统计

Tab.4 Evaluation statistics for six SCMs models in Zhidan watershed

\begin{tabular}{|c|c|c|c|c|c|c|c|c|}
\hline \multirow{2}{*}{ 模型 } & \multicolumn{4}{|c|}{ 率定期 } & \multicolumn{4}{|c|}{ 验证期 } \\
\hline & $\operatorname{Re} / \%$ & $Q e / \%$ & $\mathrm{Te} / \%$ & $D c$ & $\operatorname{Re} / \%$ & $Q e / \%$ & $\mathrm{Te} / \%$ & $D c$ \\
\hline SCM1 & 46.6 & 20.0 & 80.0 & -1.8 & 20 & 20 & 40 & -15.34 \\
\hline SCM2 & 26.6 & 26.6 & 80.0 & -5.7 & 20 & 20 & 60 & -24.03 \\
\hline SCM3 & 33.3 & 40.0 & 80.0 & -8.7 & 20 & 40 & 60 & -26.62 \\
\hline SCM4 & 40.0 & 40.0 & 73.3 & -5.6 & 20 & 40 & 80 & -22.59 \\
\hline SCM5 & 53.3 & 53.3 & 93.3 & -5.9 & 40 & 40 & 80 & -23.65 \\
\hline SCM6 & 46.6 & 46.6 & 86.6 & -6.0 & 40 & 40 & 80 & -21.78 \\
\hline
\end{tabular}

3.3.2 比较组合模型 对两个研究流域中 3 种组合模型 (SCM2、SCM4 和 SCM5) 的洪峰误差误差分布进行分 析. 从表 2 可知, 在东湾流域, SCM2 模型的模拟洪峰合格率最高. 比较组合模型模拟结果的洪峰误差可以看 出, SCM2 模型模拟结果比 SCM4 模型和 SCM 5 模型更接近实测值. 比较洪峰误差小于 $20 \%$ 的洪水场次分布, $\mathrm{SCM} 2$ 模型峰值误差在 $-5 \% \sim 5 \%$ 之间的场次最多 (图 7a). 但是, 通过观察模拟结果, 对比每场洪水计算的洪 峰误差, 可以发现: 不论模拟洪峰大于还是小于实测洪水, SCM4 模型计算的洪峰均大于 SCM2 模型. 此外, $\mathrm{SCM} 4$ 模拟的 Qe 大部分集中在 $-5 \% \sim-20 \%$, 表明模拟的洪峰容易偏大 (图 7a), 这一点在图 8 中反映得更加 直观. 对比这两场次洪水过程, 1994070220 号洪水洪峰较小, SCM4 模型模拟洪峰误差偏大. 而对于 2000071220 号洪水来说, 洪水陡涨陡落, 洪峰较大, 这时 SCM4 模型模拟得洪峰比 SCM2 模型更接近实测值.

$\mathrm{SCM} 2$ 模型和 SCM4 模型都在蓄满主导子流域中使用 XAJ 模型, 但在超渗主导子流域, SCM2 使用 XAJG 模型, 而 SCM4 选择 $\mathrm{GA}$ 模型. 对比分析两种模型的参数, 蓄满产流参数基本一致, 而超渗产流参数有所差异 ( SCM2 模型的 $\mathrm{K}_{\mathrm{S}}$ 为 $22.50, \mathrm{SCM} 4$ 模型的 $\mathrm{K}_{\mathrm{s}}$ 为 30.1 ). 在 XAJG 模型中, 一部分降雨人渗后补充土壤缺水, 所 以在相同的降雨强度下, GA 模型比 XAJG 模型产生更多的地表径流, 并且降雨强度越大, 产生的超渗地表径 流越多 ${ }^{[33]}$. 这说明 SCM4 模型倾向于高估模拟流量,使其对于峰值大的洪水事件有良好的适应性.

从表 3 可以看出, 在志丹流域, SCM5 模型的径流深合格率 $R e$ 和洪峰合格率 $Q e$ 最大. 但观察模拟结果 发现, SCM4 模型的误差范围是 3 种组合模型中最小的, 而 SCM2 模拟的峰值误差范围是最大的. 此外,SCM4 和 SCM 5 模型的峰值误差在 $-5 \% \sim 5 \%$ 之间的洪水场次数最多 (图 7b). 在 SCM 4 和 SCM 5 模型中, GA 模型用 于超渗子主导流域,但蓄满主导子流域,SCM4 选择 XAJ 模型,SCM5 选择 XAJG 模型. 因此, 在蓄满主导子流 域内,SCM5 模型比 SCM4 模型多一部分非蓄满区产生的超渗地表径流. 因此,SCM5 模型模拟的峰值误差范
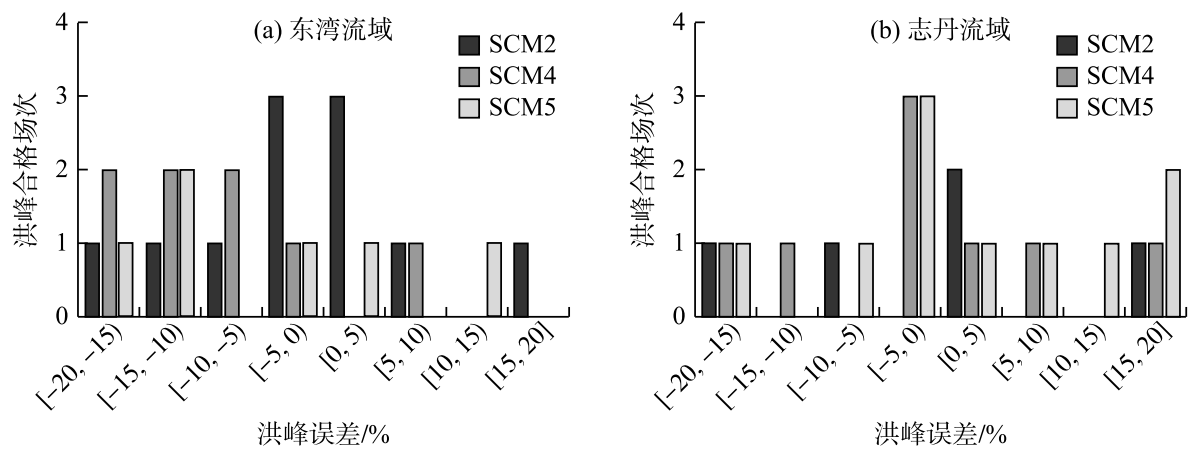

图 7 组合模型洪峰误差小于 $20 \%$ 洪水事件的分布

Fig.7 Distribution of flood events with flood peak error less than $20 \%$ in combined models 

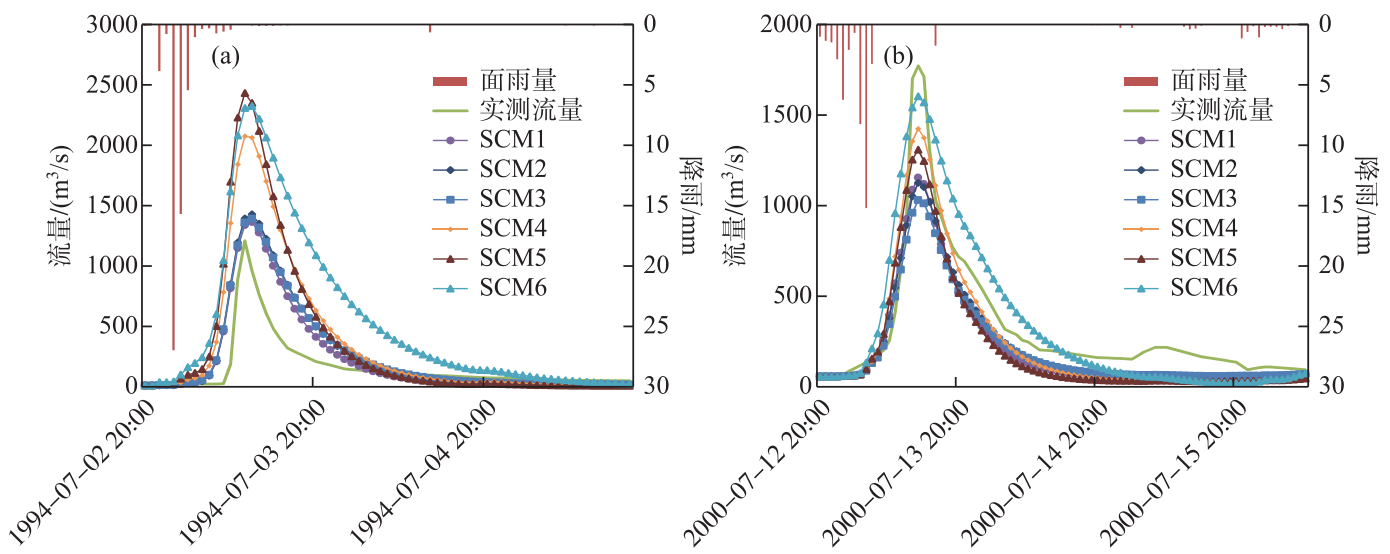

图 8 东湾流域 1994070220 号 (a) 和 2000071220 号 (b) 洪水实测与模拟洪水过程线的对比

Fig.8 Comparison of observed and simulated flood hydrograph of $1994070220^{\#}$ (a) and $2000071220^{\#}(\mathrm{~b})$ in Dongwan watershed

围稍大于 SCM4 模型(图 9).
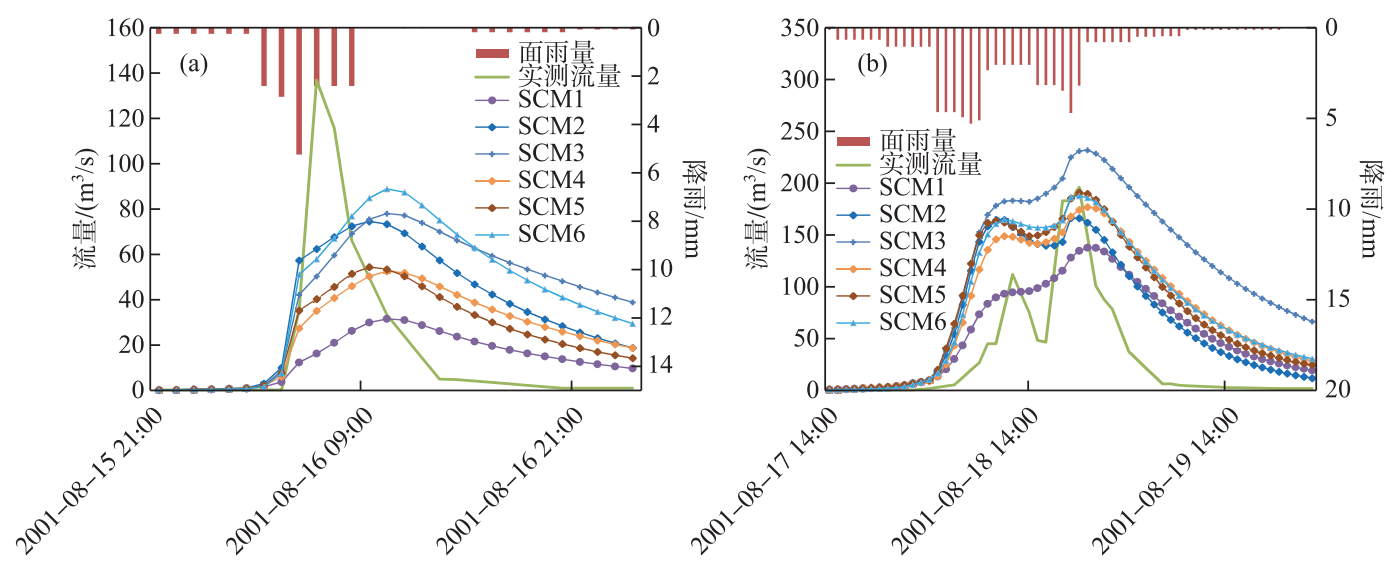

图 9 志丹流域 2001081518 号 (a) 和 2001081708 号 (b) 洪水实测与模拟洪水过程线的对比

Fig.9 Comparison of observed and simulated flood hydrograph of $2001081518^{\#}$ (a) and $2001081708^{\#}$ (b) in Zhidan watershed

3.3.3 比较非组合模型和组合模型 将模拟效果较好的非组合模型和组合模型进行比较. 在东湾流域, 从表 2 可以看出 SCM1 模型和 SCM 2 模型的模拟结果较其他模型好. 然而, 对于洪峰误差在 $-5 \% \sim 5 \%$ 范围内, SCM2 模型的洪水场次数是 SCM1 模型的 3 倍(图 10a). 因此,SCM2 模型在组合 XAJ 模型和 XAJG 模型后, 模拟峰值优于 SCM1 模型.

在志丹流域, SCM5 模型和 SCM6 模型的模拟结果较好. 对于洪峰误差在-10\% 10\%范围内,SCM5 模型 洪水场次数是 SCM6 模型的两倍(图 10b). 而 SCM6 模型模拟的洪水事件误差大多数集中在 $-20 \% \sim-10 \%$ 和 $10 \% \sim 20 \%$. 因为 SCM5 中的 XAJG 模型需要先补充土壤缺水, 可以较好地模拟在降水很大的情况下洪峰却 很小的洪水过程, 从而更加适应志丹流域.

综上所述, 在半湿润的东湾流域, 偏蓄满模型模拟结果优于偏超渗模型, 其产流机制主要是蓄满产流, 并包含少量超渗产流, 因此 SCM2 模型是最适合的. 在半干旱的志丹流域, 偏超渗模型模拟结果优于偏蓄满 模型, 但其产流机制并非所有都是超渗, 适当地增加少量蓄满产流的 SCM5 模型可以获得更好的模拟效果. 


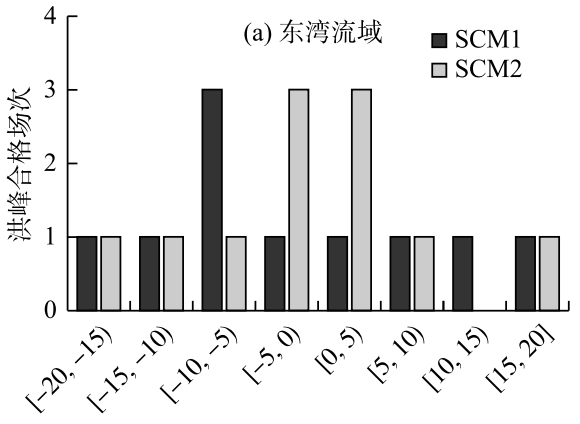

洪峰误差 $/ \%$

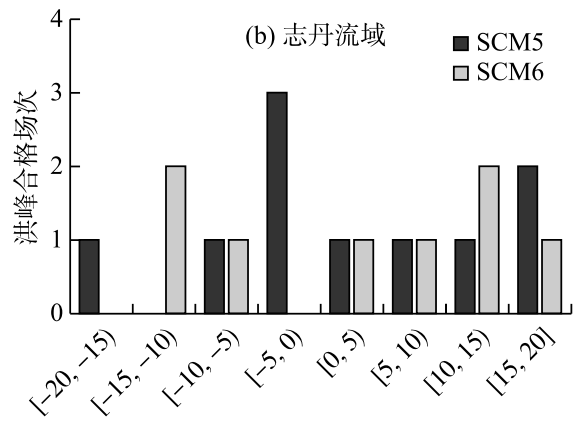

洪峰误差 $/ \%$

图 10 非组合模型和组合模型洪峰误差小于 $20 \%$ 的洪水事件的分布

Fig.10 Distribution of flood events with flood peak error less than $20 \%$ in non-combined model and combined model

\section{4 结论}

基于空间组合建模框架,选择新安江模型、新安江-Green-Ampt 模型和 Green-Ampt 模型来构建空间组合 模型 $(\mathrm{SCMs})$. 在 $\mathrm{SCMs}$ 模型中, 使用 $C N$-地形指数法将流域划分为超渗主导和蓄满主导子流域. 以半湿润流 域和半干旱流域为例进行模型检验, 研究结论如下:

1) 在半湿润的东湾流域, SCMs 模型参数由水文模型来主导, 参数取值受所选的模型影响较大. 而志丹 流域超渗比例大, 参数取值具有明显的共性,在流域主导产流机制下,参数不再受限于模型结构.

2) $C N$-地形指数法可以根据流域下垫面特征划分蓄满和超渗主导子流域,能够较好地反映各个子流域 的蓄超状态. 相比单个模型,组合模型可以更合理地捕获流域中蓄满和超渗的产流过程.

3) SCM2 和 SCM5 模型分别在半湿润和半干旱流域模拟效果最好. 将单一产流模型 (XAJ 模型或 GA 模 型) 与混合产流模型 (XAJG 模型) 相结合, 可以提高 SCMs 的精度. SCM4 模型 (XAJ 与 GA 的模型组合) 倾向 于高估模拟流量,因此更适合于量级大的洪水过程.

SCMs 模型的结构灵活,模型之间组合多变,可针对不同产流模式的研究流域选择相适应的计算方式. 但是在实际情况下, 前期土壤含水量对洪水模拟有重要影响. 在未来的研究中, 我们将在蓄超子流域划分中 考虑前期土壤含水量 ${ }^{[27]}$, 并且探索不同径流产生机制的时间动态分布规律, 进一步揭示半湿润半干旱地区 洪水形成机理.

\section{5 参考文献}

[ 1 ] WMO ed. Manual on flood forecasting and warning. Geneva: World Meteorological Organization, 2011, MMO-No1072.

[ 2 ] Huo W, Li Z, Li Q. Hydrological models comparison and ensemble forecasting in semi-humid watersheds. J Lake Sci, 2017, 29(6) : 1491-1501. DOI: 10.18307/2017.0621. [霍文博, 李致家, 李巧玲. 半湿润流域水文模型比较与集合 预报. 湖泊科学, 2017, 29(6): 1491-1501.]

[ 3 ] Li Z, Huang P, Yao C et al. Application of flexible-structure hydrological models in different runoff generation regions. Advances in Water Science, 2014, 25(1): 28-35. [李致家, 黄鹏年, 姚成等. 灵活架构水文模型在不同产流区的应用. 水科学进展. $2014,25(1): 28-35$. ]

[ 4 ] Hassan SMT, Lubczynski MW, Niswonger RG et al. Surface-groundwater interactions in hard rocks in Sardon catchment of western Spain: An integrated modeling approach. Journal of Hydrology, 2014, 517: 390-410.

[ 5 ] Bao WM, Wang CL. Vertical mixed flow model and its application. Hydrology, 1997, (3): 18-21. [包为民, 王从良. 垂 向混合产流模型及应用. 水文, 1997, (3): 18-21.]

[ 6 ] Hao GR, Li JK, Song LM et al. Comparison between the TOPMODEL and the Xin'anjiang model and their application to rainfall runoff simulation in semi-humid regions. Environmental Earth Sciences, 2018, 77(7) : 279. DOI : 10.1007/s12665- 
018-7477-4.

[ 7 ] LI Z, Hu W, Ding J et al. Study on distributed hydrological model of solving physical equation on grids. Journal of Hydroelectric Engineering, 2013, 31(2) : 5-13. [李致家, 胡伟升, 丁杰等. 基于物理基础与基于栅格的分布或水文模型研 究. 水力发电学报, 2012, 31(2): 5-13.]

[ 8 ] Williams JR, LaSeur WV. Water yield model using SCS curve numbers. Journal of the Hydraulics Division, 1976,102 (9) : 1241-1253.

[ 9 ] Chen RS, Pi LC. Diffusive tank model application in rainfall-runoff analysis of upland fields in Taiwan. Agricultural Water Management, 2004, 70: 39-50.

[10] Li ZJ, Huang PN, Zhang YP et al. Study on spatial combination model of infiltration-excess and saturation-excess runoff in semi-humid watersheds. Yellow River, 2015, 37(10): 1-6. [李致家, 黄鹏年, 张永平等. 半湿润流域蓄满超渗空间组 合模型研究. 人民黄河. $2015,37(10): 1-6$.

[11] Li ZJ, Kong XG, Zhang CW. Improving Xin'anjiang model. Hydrology, 1998, (4) : 20-24. [李致家, 孔祥光, 张初旺. 对新安江模型的改进. 水文, 1998, (4): 20-24.]

[12] Huang P, Li Z, Yao C et al. Application and comparison of hydrological models for semi-arid and semi-humid regions. Journal of Hydroelectric Engineering, 2013, 32(4): 4-9. [黄鹏年, 李致家, 姚成等. 半干旱半湿润流域水文模型应 用与比较. 水力发电学报, 2013, 32(4): 4-9.]

[13] Clark MP, Kavetski D, Fenicia F. Pursuing the method of multiple working hypotheses for hydrological modeling. Water Resources Research, 2011, 47(9) : 178-187.

[14] Hassan SMT, Lubczynski MW, Niswonger RG et al. Surface-groundwater interactions in hard rocks in Sardon Catchment of western Spain: An integrated modeling approach. Journal of Hydrology, 2014, 517: 390-410.

[15] Savenije HHG. HESS opinions: “Topography driven conceptual modelling (FLEX-Topo)”. Hydrology \& Earth System Sciences Discussions, 2010, 7(4) : 2681-2692.

[16] Euser T, Winsemius HC, Hrachowitz M et al. A framework to assess the realism of model structures using hydrological signatures. Hydrology and Earth System Sciences, 2013, 17(5) : 1893-1912.

[17] Li J, Wang Z, Liu C. A combined rainfall infiltration model based on Green-Ampt and SCS-curve number. Hydrological Processes, 2015, 29(11) : 2628-2634.

[18] Clark MP, Slater AG, Rupp DE et al. Framework for Understanding Structural Errors (FUSE) : A modular framework to diagnose differences between hydrological models. Water Resources Research, 2008, 44(12). DOI: 10.1029/2007wr006735.

[19] Buytaert W, Beven K. Models as multiple working hypotheses: Hydrological simulation of tropical alpine wetlands. Hydrological Processes, 2011, 25(11) : 1784-1799. DOI: 10.1002/hyp.7936.

[20] Gao H, Hrachowitz M, Fenicia F et al. Testing the realism of a topography driven model (FLEX-Topo) in the nested catchments of the Upper Heihe, China. Hydrology and Earth System Sciences, 2014, 18(10) : 12663-12716.

[21] Soil Conservation Service Engineering Division. Urban hydrology for small watersheds. U. S. Department of Agriculture, 1986, Technical Release 55.

[22] Beven KJ, Kirkby MJ. A physically based, variable contributing area model of basin hydrology. Hydrological Sciences Journal, 1979, 24(1): 43-69.

[23] Huang P, Li Z, Chen J et al. Event-based hydrological modeling for detecting dominant hydrological process and suitable model strategy for semi-arid catchments. Journal of Hydrology, 2016, 542: 292-303.

[24] Zhao R. The Xinanjiang model applied in China. Journal of Hydrology, 1992, 135(1/2/3/4) : 371-381.

[25] Li ZJ, Yao C, Wang ZH. Development and application of grid-based Xinanjiang model. Journal of Hohai University: Natural Sciences, 2007, 35(2): 131-134. [李致家, 姚成, 汪中华. 基于栅格的新安江模型的构建和应用. 河海大学学 报: 自然科学版, 2007, 35 (2): 131-134.]

[26] Green WH, Ampt GA. Studies on soil physics. The Journal of Agricultural Science, 1911, 4(1) : 1-24.

[27] Zhao RJ ed. Hydrological modeling of watershed. Beijing: Water Resources and Electric Power Press, 1984: 1-10. [赵人 俊. 流域水文模拟. 北京: 水利电力出版社, 1984: 1-10.]

[28] Duan Q, Sorooshian S, Gupta V. Effective and efficient global optimization for conceptual rainfall-runoff models. Water Resources Research, 1992, 28(4) : 1015-1031.

[29] Ministry of Water Resources Information Center ed. Standard for hydrological information and hydrological forecasting. Bei- 
jing: China Water Power Press, 2000. [水利部信息中心. 水文情报预报规范. 北京: 中国水力发电出版社, 2000.]

[30] Liu Y, Li Z, Liu Z et al. TOPKAPI-based flood simulation in semi-humid and semi-arid regions. Water Power, 2016,42 (1) : 18-22. [刘玉环, 李致家, 刘志雨等. 半湿润半干旱地区 TOPKAPI 模型的洪水模拟. 水力发电, 2016,42 (1) : 18-22.]

[31] Zhang HC, Li ZJ, Zhong L et al. The application and research of CASC2D model in semi-humid and semi-arid areas. China Rural Water and Hydropower, 2015, (10): 62-65. [张汉辰, 李致家, 钟栗等. CASC2D 模型在半湿润半干旱地区 的应用与研究. 中国农村水利水电, 2015, (10): 62-65.]

[32] Li ZJ, Jiang TT, Huang PN et al. Impact and analysis of watershed precipitation and topography characteristics on model simulation results. Advances in Water Science, 2015, 26(4): 473-480. [李致家, 姜婷婷, 黄鹏年等. 降雨和地形地貌 对水文模型模拟结果的影响分析. 水科学进展, 2015, 26(4): 473-480.]

[33] Rui XF ed. Principles of hydrology. Beijing: China Water Power Press, 2004: 86-99. [茌孝芳. 水文学原理. 北京: 中 国水利水电出版社, 2004: 86-99.] 